\title{
A Comparison of 5, 10, 30 Meters Sprint, Modified T-Test, Arrowhead and Illinois Agility Tests on Football Referees
}

\author{
Surhat Muniroglu ${ }^{1}$, Erdem Subak ${ }^{1}$ \\ ${ }^{1}$ Ankara University Faculty of Sport Sciences, Turkey \\ Correspondence: Surhat Muniroglu, Ankara University Faculty of Sport Sciences, Turkey.
}

Received: May 14, 2018

Accepted: June 7, 2018

Online Published: June 11, 2018

doi:10.11114/jets.v6i8.3360

URL: https://doi.org/10.11114/jets.v6i8.3360

\begin{abstract}
The ability of change of direction quickly, in other words agility, and short distance sprinting speed are two of the most important performance components for football referees. The tests used by FIFA and UEFA such as Cooper Test, Yo-Yo Intermittent Test, $40 \times 75 \mathrm{~m}$ tests do not include testing the agility skills of the referees. However, especially the field referees changing their activities constantly. Otherwise, the short distance sprinting is another important factor to well positioning of the football referees. Especially, the assistant referees frequently performs short sprints to follow the offside line. For these reasons, we have compared $5 \mathrm{~m}, 10 \mathrm{~m}, 30 \mathrm{~m}$ sprint tests, T-Test, Arrowhead Agility Test and Illinois Agility Test scores of the football referees working in Ankara (City referees). All referees performed sprint tests twice and performed the agility tests one time. All tests have shown normal distribution frequencies. Our results showed that all of the six tests have shown positive correlations between $(P<0,01)$. Additively, it could be said that the agility skill has a relationship with short distance sprinting because of the referees who showed better sprint performances were also found to have higher agility scores. Consequently, each of the $5 \mathrm{~m}, 10 \mathrm{~m}, 30 \mathrm{~m}$, T-Test, Arrowhead and Illinois Agility Test could be used to assess the performance of the referees.
\end{abstract}

Keywords: agility, Arrowhead, football referees, Illinois, sprint tests, T-Test

\section{Introduction}

Speed and agility are two of the most important performance components for success on the football. It has been shown that the players has spent about 22 minutes (2,6\% of total time) at high speed running and sprinting (>19,8 km.h-1) in the Premier League (Bradley et al., 2009). As well as the footballers, the referees are in physical activity at a significant level during the match. Moreover, Weston et al. showed that the total distance covered by referees $(11,280+738 \mathrm{~m})$ were greater than the players $(10,794+374 \mathrm{~m})$ in Premier Leauge. The referees covered approximately 869 meters of that total distance at high-speed and by sprinting (Weston, Drust, \& Gregson, 2011).

The agility skill is as important as speed for referees' performance. To be close to the positions, the referees must be successfully for various movements during game like changing direction quickly, side stepping and back stepping. Furthermore, 1268 activity changes (1053 for assistant referees) has been reported in Danish elite football referees (Helsen \& Bultynck, 2004; Krustrup \& Bangsbo, 2001; Krustrup, Mohr, \& Bangsbo, 2002).

Some of the tests has been used by FIFA (International Union of Association Football) and UEFA (European Union of Association Football) to the selection of the football referees. Most used tests by FIFA and UEFA are the Cooper Test, $40 \times 75 \mathrm{~m}$ interval test, $20 \times 150 \mathrm{~m}$ interval test, $6 \times 40 \mathrm{~m}$ sprint test, Yo-Yo Intermittent Test and CODA Test (Castagna, Abt, \& D'Ottavio, 2005; Castagna, Impellizzeri, Bizzini, Weston, \& Manzi, 2011; Weston, Castagna, Helsen, \& Impellizzeri, 2009). The Cooper test includes 12 minutes straight running and the test is used calculating maximal oxygen intake (Cooper, 1968). Also, $40 \times 75 \mathrm{~m}$ and $20 \times 150 \mathrm{~m}$ interval tests include straight runnings. All of these tests excepting the CODA test are include straight runnings and does not include changing of directions. However, the football referees must have a great skill of changing direction quickly to be the close to the positions and making the true-decisions during a match. Additively, although the CODA test has been used to test performance of assistant referees, Castagna et al. showed that the CODA test has no significant performance differences were found between competitive levels (Castagna et al., 2011).

In this study, we applied 6 performance tests to the referees. Half of these tests were sprint tests and the other half were agility tests. The first three tests were 5 meters, 10 meters and 30 meters sprint tests. Especially, the assistant referees 
have a 52,5-60 meters (For a field with FIFA standards) moving line to perform on a football match. Therefore the short distance sprints are notably important for assistant referees. Additively, the explosiveness and the sprint speeds of the assistant referees are very important to follow properly the offside line.

Our last three tests were the T-Test, Arrowhead Test, Illinois Agility Test. Many studies showed the 5, 10 and 30 meters sprint tests were related the sprint ability of the athletes (Duthie, Pyne, Ross, Livingstone, \& Hooper, 2006; Köklü, Alemdaroğlu, Özkan, Koz, \& Ersöz, 2015; Marques, Gil, Ramos, Costa, \& Marinho, 2011; Miller, Herniman, Ricard, Cheatham, \& Michael, 2006). And the studies showed the relation of the agility skills of the athletes and the T-Test, Arrowhead Agility Test and Illinois Agility Test (Amiri-Khorasani, Sahebozamani, Tabrizi, \& Yusof, 2010; Chan, Lee, Fong, Yung, \& Chan, 2011; Jalilvand et al., 2015; Miller et al., 2006; Muniroglu \& Subak, 2018). Especially, agility is an essential skill for the field referees. Because, the field referees should perform side steps, back steps, changing of directions quickly, sudden turning backs etc. successfully during the game. In addition, side stepping is an essential skill for the assistant referees and the T-Test has a side stepping part (Muniroglu \& Subak, 2018).

The importance of the short sprinting skills and the agility skills of soccer referees is obvious. And the tests have been used by FIFA do not exactly measure these abilities. The aim of this study was finding reliable sprint and agility tests for soccer referees. For this purpose, we have compared the 5 meters sprint, 10 meters sprint, 30 meters sprint, Arrowhead Agility Test, T-Test and Illinois Agility Test scores of the 72 male soccer referees in Ankara (Turkey).

\section{Methods}

\subsection{Participants}

72 male football referees (city referees, mean age 23,51 $\pm 2,69$ ) in Ankara (Turkey) participated in this study. All referees signed the approval forms. All referees have regularly participated in trainings and matches. The height (mean $180,50 \pm 5,19$ ) and weight (mean 73,51 $\pm 7,94$ ) informations of the all referees were recorded.

\subsection{Test Protocols}

All tests practiced on the synthetic turf, in the Ankara 19 Mayis Stadium training pitches. At the time of the tests, the temperature was $22^{\circ} \mathrm{C}$. All referees performed the 5, 10 and 30 meter sprint tests twice and performed the T-Test, Arrowhead and Illinois Tests one time. Before the tests, all referees participated 20 minutes warm-up workout. At the waiting times of the between tests, all referees were keeped active by jumping rope and stretching exercises to avoid cool down.

\subsection{5-10-30 Meters Tests Protocols}

5 meters, 10 meters and 30 meters sprint tests has similar protocols. The photocells settled the starting and finishing points of the distance 5 meters, 10 meters and 30 meters. All referees have started from 1 meter behind of the starting photocell. Best scores of the referees were recorded.

\subsection{T-Test Protocol}

We have used our previous modified T-Test protocol that has been shown in Figure 1 (Muniroglu \& Subak, 2018) (Figure 1A). $40 \mathrm{~cm}$ height cones have been used. All referees have started 1 meter behind of the starting photocell. The referees must touch the cones with hand when they reached. Firstly, the referee runs 10 meters forward as quickly as possible, then run to the right by side steps, 5 meters along. After, the referee runs by side steps to the left, 10 meters along. Again, the referee runs to the center cone by side steps, 5 meters along. Then he runs by back steps, 5 meters along. Finally, he turns back as much as quickly and sprint to the finishing photocell.

\subsection{Arrowhead Agility Test Protocol}

We have used the protocol used by Jalilvand et al. for the Arrowhead Agility Test as showed in the figure 1B (Figure 1B) (Jalilvand et al., 2015). All referees have started 1 meter behind of the photocell. In the beginning of the test, the referees sprint to the middle cone and turn from outside of the cone to the left or right what they want. After, referees turn around the left/right cone and around the upper cone. Finally, referees sprint to the finishing photocell. 


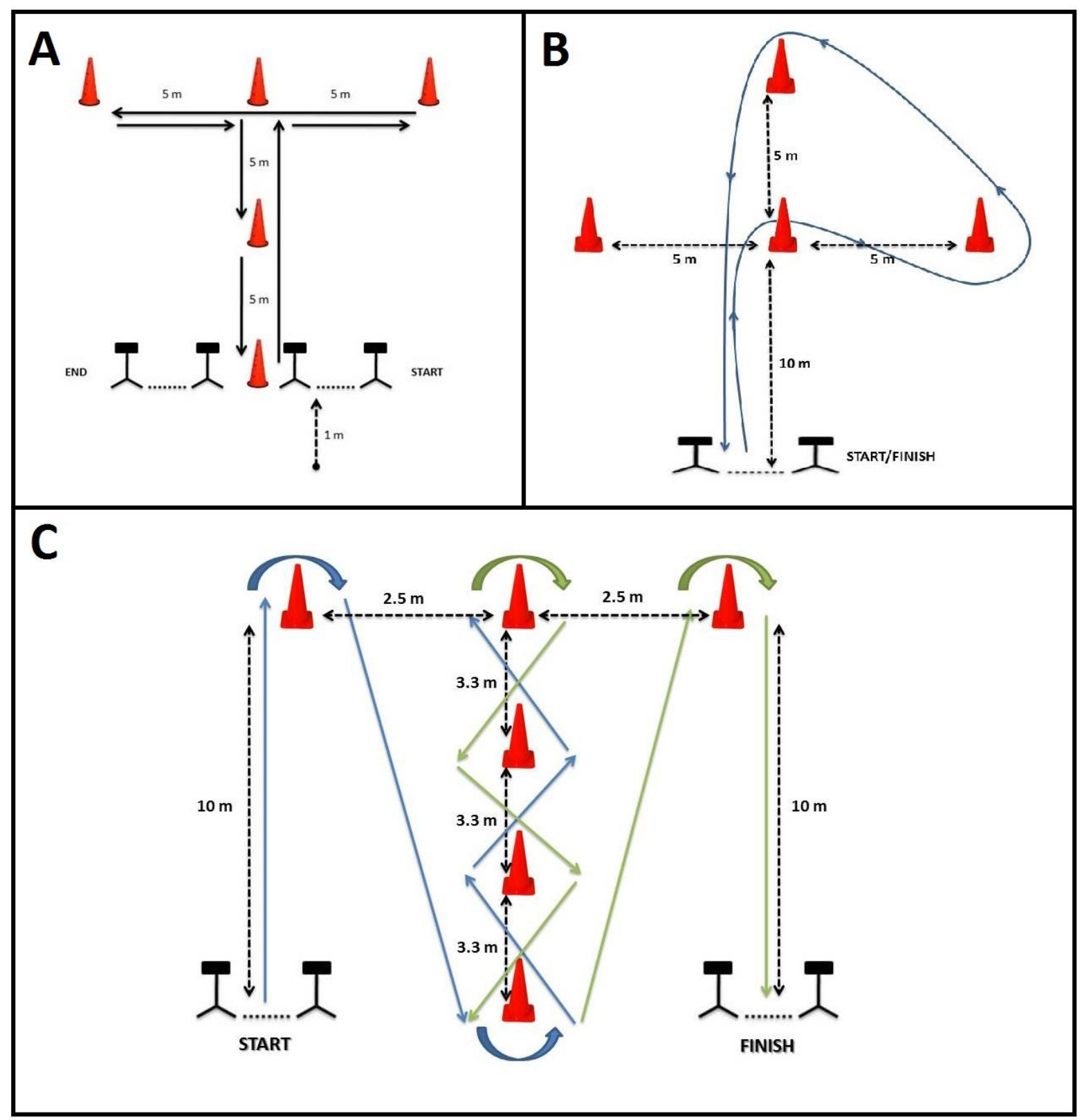

Figure 1. A. T-Test, B. Arrowhead Agility Test, C. Illinois Agility Test

\subsection{Illinois Agility Test Protocol}

For the Illinois Agility Test, we have used the standard protocol used in many studies (Amiri-Khorasani et al., 2010; Negra et al., 2017; Raya et al., 2013). Firstly, the referees have sprinted to the left cone and turned around it. After, the referees have run to the first middle cone standing in the starting line then turned around it. All referees have passed the cones with zigzag move as shown in Figure 1C (Figure 1C). Lastly, the referees have sprinted to the finishing photocell.

\subsection{Statistical Analyses}

We have used the IBM SPSS Statistics 24.0 to statistical analyses. The histogram analysis was made and graphed for all tests (Figure 2). Linear regression and Pearson Product Moment Correlation analysis were used to determine the statistical relationship of all tests. The significance level was settled at $P<0,01$.

\section{Results}

72 active football referees have participated all of the 6 tests. The mean age, height and weight of the participants were $23,51 \pm 2,69,180,50 \pm 5,19,73,51 \pm 7,94$. The histogram graphics of the age, height, weight and all tests have shown normal distribution (Figure 2). Mean scores for all tests have shown in Table 1 (Table 1). 


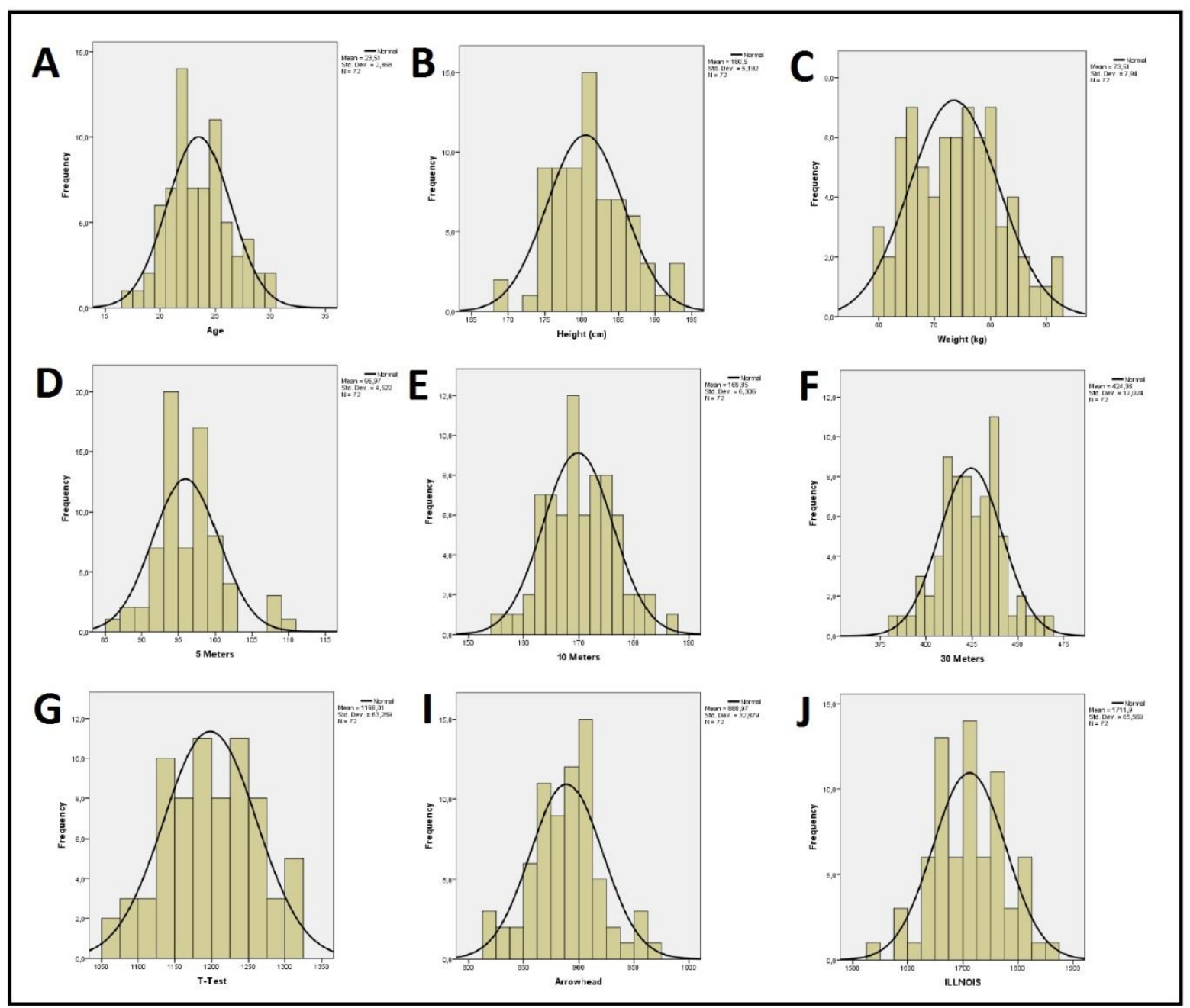

Figure 2. Frequency distributions. A. Age, B. Height, C. Weight, D. 5 m, E. 10 m, F. 30 m, G. T-Test, I. Arrowhead Agility Test, J. Illinois Agility Test

The Pearson Product Moment Correlation analyses showed that all of the tests have had positive correlation between each other. According to the results of correlation analyses; $5 \mathrm{~m}-10 \mathrm{~m}(r=0,726, P<0,01), 5 \mathrm{~m}-30 \mathrm{~m}(r=0,626, P$ $<0,01), 10 \mathrm{~m}-30 \mathrm{~m}(r=0,847, P<0,01), 10 \mathrm{~m}-$ T-Test $(r=0,426, P<0,01), 10 \mathrm{~m}-$ Arrowhead $(r=0,576, P<$ 0,01), $10 \mathrm{~m}$ - Illinois $(r=0,603, P<0,01), 30 \mathrm{~m}-$ T-Test $(r=0,484, P<0,01), 30 \mathrm{~m}-$ Arrowhead $(r=0,706, P<$ 0,01), $30 \mathrm{~m}$ - Illinois $(r=0,752, P<0,01)$, T-Test - Arrowhead $(r=0,501, P<0,01)$, T-Test - Illinois $(r=0,614, P<$ $0,01)$ and Arrowhead - Illinois $(r=0,792, P=0,01)$ tests have shown very high correlations (Table 2). Besides, the $5 \mathrm{~m}$ - T-Test $(r=0,310, P=0,01), 5 \mathrm{~m}$ - Arrowhead $(r=0,389, P=0,01)$ and $5 \mathrm{~m}-$ Illinois $(r=0,399, P=0,01)$ have shown weak positive correlations. Additively, the linear regression analyses have shown significance for all groups $(P<$ $0,01)$.

Table 1. Mean test scores of 72 football referees.

\begin{tabular}{|l|c|c|}
\hline \multicolumn{1}{|c|}{ Test } & Mean (s) & Sd \\
\hline $\mathbf{5 ~} \mathbf{~}$ & 0,95 & 0,04 \\
\hline $\mathbf{1 0} \mathbf{~}$ & 1,7 & 0,06 \\
\hline $\mathbf{3 0} \mathbf{~}$ & 4,24 & 0,17 \\
\hline $\mathbf{T}-$ Test & 11,98 & 0,63 \\
\hline Arrowhead & 8,89 & 0,33 \\
\hline Illinois & 17,12 & 0,66 \\
\hline
\end{tabular}

We have also analysed the correlations between of the age, height, weight values with the all tests. However, the analyses have not shown significant correlations. 
Table 2. Results of correlation analysis $(P<0,01)$

\begin{tabular}{|l|c|}
\hline \multicolumn{1}{|c|}{ Test } & $r$ \\
\hline $5 \mathrm{~m}-10 \mathrm{~m}$ & 0,726 \\
\hline $5 \mathrm{~m}-30 \mathrm{~m}$ & 0,626 \\
\hline $10 \mathrm{~m}-30 \mathrm{~m}$ & 0,847 \\
\hline $5 \mathrm{~m}$ - T-Test & 0,726 \\
\hline $5 \mathrm{~m}$ - Arrowhead & 0,389 \\
\hline $5 \mathrm{~m}$ - Illinois & 0,399 \\
\hline $10 \mathrm{~m}$ - T-Test & 0,426 \\
\hline $10 \mathrm{~m}$ - Arrowhead & 0,576 \\
\hline $10 \mathrm{~m}$ - Illinois & 0,603 \\
\hline $30 \mathrm{~m}$ - T-Test & 0,484 \\
\hline $30 \mathrm{~m}$ - Arrowhead & 0,706 \\
\hline $30 \mathrm{~m}$ - Illinois & 0,752 \\
\hline T-Test - Arrowhead & 0,501 \\
\hline T-Test - Illinois & 0,614 \\
\hline Arrowhead - Illinois & 0,792 \\
\hline
\end{tabular}

\section{Discussion}

In this study, we have compared the short distance sprint skills $(5,10$ and $30 \mathrm{~m})$ and agility skills of the 72 football referees. According to the histogram analyses, our group has shown normal distribution of all parameters (age, weight, height and all test scores) (Figure 2). And this results have shown that we have a favorable sample to compare test scores meaningly.

Previously, Little \& Williams showed significant correlations between the $10 \mathrm{~m}, 20 \mathrm{~m}$ sprint and zigzag agility test scores in professional football players (Little \& Williams, 2005). In parallel, our results showed significant correlations between $5 \mathrm{~m}, 10 \mathrm{~m}, 30 \mathrm{~m}$ sprint tests with all of the agility tests we practiced on referees. Further, Raya et al. showed a positive higher correlation between T-Test and Illinois Agility Test scores in 97 male U.S. Army (Raya et al., 2013). Correspondingly, our results showed a positive and higher correlations between these agility tests in soccer referees.

In our previous study, we have revealed the relationship between 10 meters, 30 meters sprint skills with our modified T-Test (reliability of the test is 84\%) (Muniroglu \& Subak, 2018). We have shown once again the correlation between T-Test and $10 \mathrm{~m}-30 \mathrm{~m}$ sprint test with this study. In addition to this, we have shown that there is a positive correlation between T-Test and 5 meter sprint test. Moreover, the correlation analysis also have shown us our modified T-Test has revealed high correlations with the Arrowhead and the Illinois Agility Tests. Given these results, the modified T-Test could be an appropriate test to gain insights about the agility skills of referees.

Although all tests showed significant positive correlations in this study, $5 \mathrm{~m}$ sprint scores showed weaker positive correlations comparing to others. $5 \mathrm{~m}$ sprinting performance requires some other special skills such as explosiveness and techniques such as correct starting position (Duthie et al., 2006; Marques et al., 2011; Mendoza \& Schöllhorn, 1993). So that, these weaker correlations might be affected by the wrong starting techniques and the difference of the explosiveness skills of the football referees. However, $5 \mathrm{~m}$ sprint scores have shown a high correlation with T-Test scores $(r=0,726)$. T-Test is not a continuous running test and includes a number of stopping and re-activation phases. Therefore, this is the main difference of the T-Test from Arrowhead and Illinois tests. Hereby, this could be the reason why the T-Test and the 5-m sprint test has shown a high correlation. Similarly, $5 \mathrm{~m}$ has shown weaker correlations with Arrowhead and Illinois Agility Tests (Table 2).

Unlike the tests has been used by FIFA and UEFA; T-Test, Arrowhead Agility Test and Illinois Agility Test includes agility skill more predominantly. T-Test include side steps exactly used by assistant referees. The Arrowhead and Illinois Agility Tests includes quickly change of direction skills predominantly used by field referees. Our study has shown that the T-Test, Arrowhead and Illinois Agility Test able to more specifically measure the referees' performance. Because, these tests include the movements especially that the referees performs in the field.

In addition to these results, this study showed there is a strong relationship between short distance sprint and agility performance. Our previous study has also showed this result (Muniroglu \& Subak, 2018). As a result of our studies, the referees who showed better sprint performances were also found to have higher agility scores. And the referees who 
scored worse sprint performances had lower agility scores. Although short distance sprint speed and agility performances have relation, Young et al. showed that the training of these two skills should be spesific to the skill desired to be improved (Young, McDowell, \& Scarlett, 2001).

\section{Conclusion}

The tests have been used by FIFA and UEFA for referee selection have not included agility performance essentially. However, the change of direction ability is very important especially for the field referees. Also, short distance sprint speed is another critical skill for both of the field and assistant referees. Particularly, $40 \times 75 \mathrm{~m}$ test used by FIFA and UEFA might not an appropriate test for the assistant referees. Because, assistant referees perform maximum $60 \mathrm{~m}$ (half of the $120 \mathrm{~m}$ sideline) area during match. Assistant referees do not run $75 \mathrm{~m}$ distance during the match. Therefore, the short distance sprinting and the agility tests should also add to the referee selection steps. Our study showed the positive correlations between $5 \mathrm{~m}, 10 \mathrm{~m}, 30 \mathrm{~m}$ sprint, T-Test, Arrowhead and Illinois Agility Tests and these tests could be used to the referee selection stages.

\section{References}

Amiri-Khorasani, M., Sahebozamani, M., Tabrizi, K. G., \& Yusof, A. B. (2010). Acute effect of different stretching methods on Illinois agility test in soccer players. The Journal of Strength \& Conditioning Research, 24(10), 2698-2704. https://doi.org/10.1519/JSC.0b013e3181bf049c

Bradley, P. S., Sheldon, W., Wooster, B., Olsen, P., Boanas, P., \& Krustrup, P. (2009). High-intensity running in English FA Premier League soccer matches. Journal of Sports Sciences, 27(2), 159-168. https://doi.org/10.1080/02640410802512775

Castagna, C., Abt, G., \& D'Ottavio, S. (2005). Competitive-level differences in Yo-Yo intermittent recovery and twelve minute run test performance in soccer referees. Journal of Strength and Conditioning Research, 19(4), 805.

Castagna, C., Impellizzeri, F. M., Bizzini, M., Weston, M., \& Manzi, V. (2011). Applicability of a change of direction ability field test in soccer assistant referees. The Journal of Strength \& Conditioning Research, 25(3), 860-866. https://doi.org/10.1519/JSC.0b013e318208ae8e

Chan, C. K., Lee, J. W., Fong, D. T., Yung, P. S., \& Chan, K. M. (2011). The difference of physical ability between youth soccer player and professional soccer player: An training implication. Journal of Strength and Conditioning Research, 25, S1-S22.

Cooper, K. H. (1968). A means of assessing maximal oxygen intake: correlation between field and treadmill testing. Jama, 203(3), 201-204. https://doi.org/10.1001/jama.1968.03140030033008

Duthie, G. M., Pyne, D. B., Ross, A. A., Livingstone, S. G., \& Hooper, S. L. (2006). The reliability of ten-meter sprint time using different starting techniques. Journal of Strength and Conditioning Research, 20(2), 246. https://doi.org/10.1519/R-17084.1

Helsen, W., \& Bultynck, J. B. (2004). Physical and perceptual-cognitive demands of top-class refereeing in association football. Journal of Sports Sciences, 22(2), 179-189. https://doi.org/10.1080/02640410310001641502

Jalilvand, F., Mock, S. A., Stecyk, S. D., Crelling, J. B., Lockwood, J. R., \& Lockie, R. G. (2015). The Arrowhead change-of-direction speed test: reliability and relationships to other multidirectional speed assessments. Paper presented at the 38th National Strength and Conditioning Association National Conference and Exhibition, Orlando, Florida, USA.

Köklü, Y., Alemdaroğlu, U., Özkan, A., Koz, M., \& Ersöz, G. (2015). The relationship between sprint ability, agility and vertical jump performance in young soccer players. Science \& Sports, 30(1), e1-e5. https://doi.org/10.1016/j.scispo.2013.04.006

Krustrup, P., \& Bangsbo, J. (2001). Physiological demands of top-class soccer refereeing in relation to physical capacity: effect of intense intermittent exercise training. Journal of Sports Sciences, 19(11), 881-891. https://doi.org/10.1080/026404101753113831

Krustrup, P., Mohr, M., \& Bangsbo, J. (2002). Activity profile and physiological demands of top-class soccer assistant refereeing in relation to training status. Journal of Sports Sciences, 20(11), 861-871. https://doi.org/10.1080/026404102320761778

Little, T., \& Williams, A. G. (2005). Specificity of acceleration, maximum speed, and agility in professional soccer players. Journal of Strength and Conditioning Research, 19(1), 76. 
Marques, M., Gil, H., Ramos, R., Costa, A., \& Marinho, D. (2011). Relationships between vertical jump strength metrics and 5 meters sprint time. Journal of Human Kinetics, 29, 115-122. https://doi.org/10.2478/v10078-011-0045-6

Mendoza, L., \& Schöllhorn, W. (1993). Training of the sprint start technique with biomechanical feedback. Journal of Sports Sciences, 11(1), 25-29. https://doi.org/10.1080/02640419308729959

Miller, M. G., Herniman, J. J., Ricard, M. D., Cheatham, C. C., \& Michael, T. J. (2006). The effects of a 6-week plyometric training program on agility. Journal of sports science \& medicine, 5(3), 459.

Muniroglu, S., \& Subak, E. (2018). A Modified T-Test for Football Referees to Test Agility, Quickness and Sprint Performances. Journal of Education and Training Studies, 6(5), 10-15. https://doi.org/10.11114/jets.v6i5.3131

Negra, Y., Chaabene, H., Amara, S., Jaric, S., Hammami, M., \& Hachana, Y. (2017). Evaluation of the Illinois Change of Direction Test in Youth Elite Soccer Players of Different Age. Journal of human kinetics, 58(1), $215-224$. https://doi.org/10.1515/hukin-2017-0079

Raya, M. A., Gailey, R. S., Gaunaurd, I. A., Jayne, D. M., Campbell, S. M., Gagne, E., ... Tucker, C. (2013). Comparison of three agility tests with male servicemembers: Edgren Side Step Test, T-Test, and Illinois Agility Test. Journal of Rehabilitation Research \& Development, 50(7), 951-960. https://doi.org/10.1682/JRRD.2012.05.0096

Weston, M., Castagna, C., Helsen, W., \& Impellizzeri, F. (2009). Relationships among field-test measures and physical match performance in elite-standard soccer referees. Journal of Sports Sciences, 27(11), 1177-1184. https://doi.org/10.1080/02640410903110982

Weston, M., Drust, B., \& Gregson, W. (2011). Intensities of exercise during match-play in FA Premier League referees and players. Journal of Sports Sciences, 29(5), 527-532. https://doi.org/10.1080/02640414.2010.543914

Young, W. B., McDowell, M. H., \& Scarlett, B. J. (2001). Specificity of sprint and agility training methods. The Journal of Strength \& Conditioning Research, 15(3), 315-319.

\section{Copyrights}

Copyright for this article is retained by the author(s), with first publication rights granted to the journal.

This is an open-access article distributed under the terms and conditions of the Creative Commons Attribution license which permits unrestricted use, distribution, and reproduction in any medium, provided the original work is properly cited. 